Article

\title{
Improving Keeping for Octopuses by Testing Different Escape-Proof Designs on Tanks for "Big Blue Octopus" (Octopus cyanea)
}

\author{
Keishu Asada ${ }^{1}$, Ryuta Nakajima ${ }^{2}$, Takahiro Nishibayashi ${ }^{1}$, Fabienne Ziadi-Künzli ${ }^{1}$, Zdeněk Lajbner ${ }^{1}$, \\ Jonathan Miller ${ }^{1,+}$, Tamar Gutnick ${ }^{1, *,+}$ and Michael J. Kuba ${ }^{1, *,+}$ (D) \\ 1 Physics and Biology Unit, Okinawa Institute of Science and Technology Graduate University (OIST), \\ 1919-1 Tancha, Onna-son, Okinawa 904-0945, Japan; Keishu.Asada@oist.jp (K.A.); \\ Takahiro.Nishibayashi@oist.jp (T.N.); fabienne.ziadi@oist.jp (F.Z.-K.); lajbner@oist.jp (Z.L.); jm@oist.jp (J.M.) \\ 2 Department of Art and Design, University of Minnesota Duluth, 1201 Ordean Ct., Duluth, MN 55812, USA; \\ lazymonk22@gmail.com \\ * Correspondence: tamar.gutnick@mail.huji.ac.il (T.G.); michi.kuba@mac.com (M.J.K.) \\ + These authors contributed equally to this work.
}

\section{check for}

updates

Citation: Asada, K.; Nakajima, R.; Nishibayashi, T.; Ziadi-Künzli, F.; Lajbner, Z.; Miller, J.; Gutnick, T.; Kuba, M.J. Improving Keeping for Octopuses by Testing Different

Escape-Proof Designs on Tanks for "Big Blue Octopus" (Octopus cyanea). Appl. Sci. 2021, 11, 8547. https:// doi.org/10.3390/app11188547

Academic Editor: Natalija Topić Popović

Received: 18 August 2021

Accepted: 3 September 2021

Published: 14 September 2021

Publisher's Note: MDPI stays neutral with regard to jurisdictional claims in published maps and institutional affiliations.

Copyright: (c) 2021 by the authors. Licensee MDPI, Basel, Switzerland. This article is an open access article distributed under the terms and conditions of the Creative Commons Attribution (CC BY) license (https:/ / creativecommons.org/licenses/by/ $4.0 /)$.

\begin{abstract}
Octopus cyanea has a wide range of natural distribution and is interesting for scientific research. However, unlike Octopus vulgaris, the species is poorly studied, and few data exist on best practices for keeping them. One of the most common reasons for losing octopuses in human care is their ability to escape from holding tanks. Adult Octopus cyanea $(n=33)$ were locally collected in Okinawa throughout the year. All animals were housed at the laboratory facilities at the Marine Station of the Okinawa institute of Science and Technology. Animals were kept in a flow-through saltwater system in three different types of holding tanks ranging from $550 \mathrm{~L}$ to $600 \mathrm{~L}$ tanks or in $2000 \mathrm{~L}$ tanks, all with an environment enriched with clay pots or natural rocks as dens. They were fed a daily diet of dead fish or live or dead crustaceans ad libitum. To characterize the effectiveness of different keeping conditions, we compared escape attempts and non-natural deaths during the animals' time under human care. We found that two types of tanks, the $600 \mathrm{~L}$ transparent acrylic glass tanks with weighted lids and the $2000 \mathrm{~L}$ tanks with synthetic grass lined walls, had significantly fewer escapes than the $550 \mathrm{~L}$ tanks.
\end{abstract}

Keywords: octopus keeping; octopus escape; octopus laboratory

\section{Introduction}

Cephalopods and especially octopuses have fascinated scientists and the public for decades. The last 50 years have seen an increase in scientific work comparing the brains and complex behaviors of these unique invertebrates to those of vertebrates [1-4]. This increased interest has required that animals be kept in marine stations and laboratories for observation and experiments. In the 1920s, researchers reported that octopuses kept in the Zoological Station of Naples moved from their aquarium to a nearby aquarium to hunt lobsters or other prey [5,6], underscoring the difficulty in containing these escape artists. Indeed, one of the most-often reported reasons for losing octopuses in captivity has been their ability to escape keeping containers and aquariums [7] (Figure 1a). The efforts to prevent escape led to a wide variety of different keeping strategies, many of which remain unreported.

Octopuses are now commonly found not only in research settings, but also in public aquariums, and their use in commercial aquaculture is growing. Researchers have started to systematically investigate professional aquaculture of cephalopods, which requires the keeping of significantly larger numbers of animals than a typical laboratory or public aquarium (for a review see [8]). Several studies have investigated the maintaining of common octopuses in swimming containers to grow to larger sizes for the food market $[8,9]$. 
For aquaculture, speed and ease of handling are as important as preventing escape. While anecdotal reports of octopuses escaping and returning to their tanks are shared often, death is the outcome of most escapes. Therefore, in evaluating keeping methods, apart from animal welfare requirements, such as aquarium size and environmental enrichment, it is essential to take into account escape prevention and ease of handling [6,10].
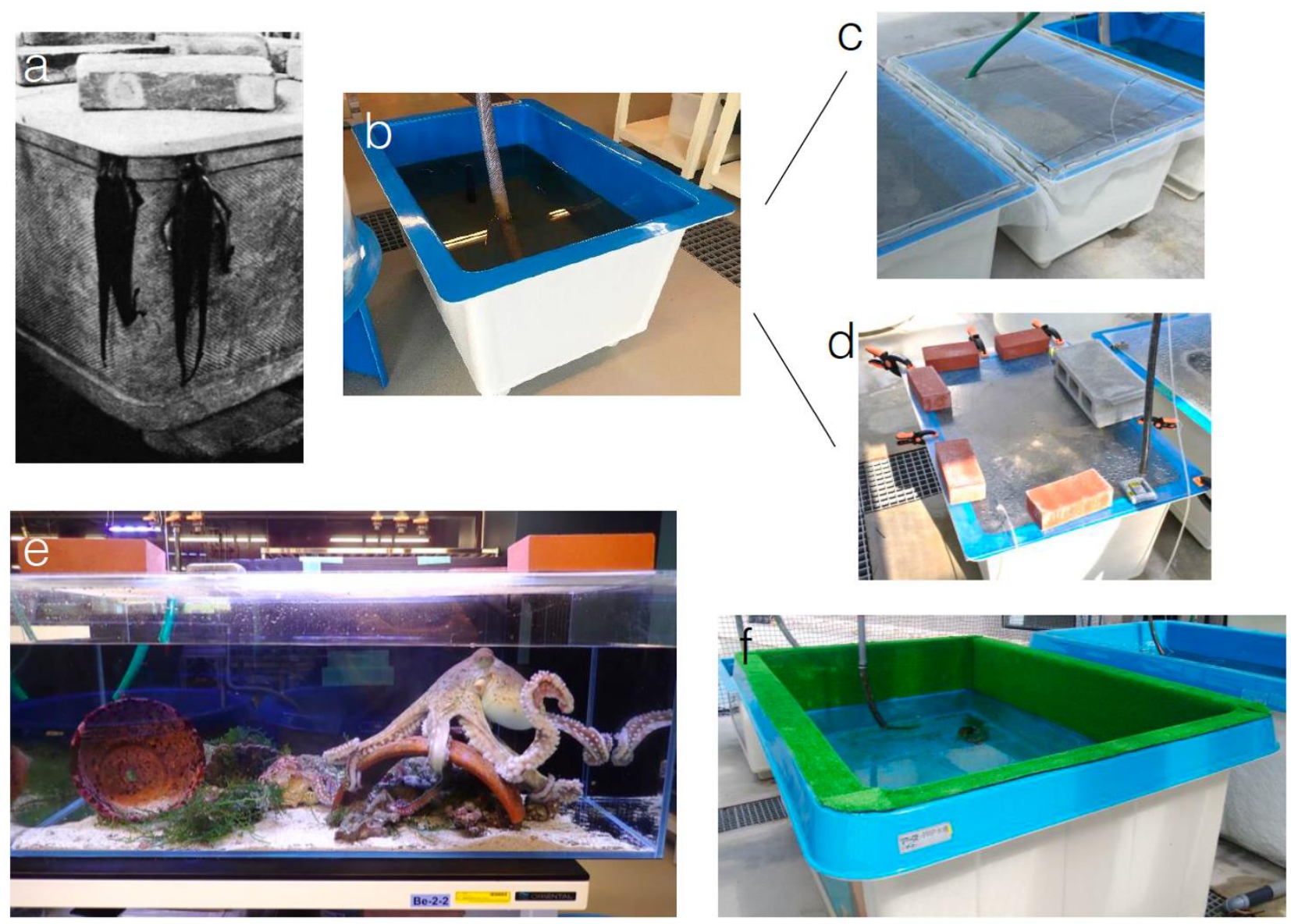

Figure 1. (a) Octopus vulgaris escapes, leading to animal loss [7]. (b) Type 1 tanks are standard 270 L aquaculture opaque tanks adapted for use with octopuses, with either (c) a net fastened into a rail, or (d) a weighted and clamped plexiglass lid. (e) Type 2 tank is a custom made 360 L plexiglass tank with weighted plexiglass lid. (f) Type 3 tanks are standard aquaculture $3000 \mathrm{~L}$ opaque tanks, with one plexiglass window, adapted for use with octopuses by lining upper interior walls and rim with artificial grass.

In the present study we report on several different sizes and types of keeping containers, as well as different types of anti-escape adaptations and their success in keeping Octopus cyanea. The usability of the anti-escape adaptations also takes into account the ease of handling (opening and closing, tank cleaning) and the ability of the caretaker to interact and evaluate the welfare of the octopus. In our study, we used Octopus cyanea, a large, tropical, day-active species, which is of great potential interest for comparative studies [3]. Compared to its temperate climate cousin, Octopus vulgaris, this species is poorly studied, and few data exist on best practices for keeping them [6,11,12].

\section{Materials and Methods}

All experimental animals were held according to the guidelines for the EU Directive 2010/63/EU for cephalopod welfare [6]. Twenty-nine Adult Octopus cyanea (1-4 kg) were locally collected in Okinawa between June 2017 and October 2018. Local fishermen caught the octopuses by net and immediately transferred them to the Marine Station of the Okinawa Institute of Science and Technology. The Marine Station provides both indoor 
and outdoor facilities with flow-through, particle-filtered, natural sea water. In addition to natural daylight, tanks indoors were illuminated by florescent lights on a 12-12 h cycle. Keeping tanks:

Tank Type $1270 \mathrm{~L}$ opaque blue tank with outward facing rim (Figure 1b-d; FRP tank, Square-type KF-270S. $(\mathrm{W} \times \mathrm{L} \times \mathrm{D}): 60 \times 90 \times 50 \mathrm{~cm}$ ).

Tank Type $2360 \mathrm{~L}$ transparent acrylic tanks with inward facing rim (Figure 1e; Custom design, Exotic Aquaria $(\mathrm{W} \times \mathrm{L} \times \mathrm{D}): 60 \times 120 \times 50 \mathrm{~cm}$ with corner weir).

Tank Type 33000 L opaque blue tank with one acrylic window and with outward-facing lip on the top (Figure 1f; FRP tank Square-type w/acryl window KF-3000SSA-L $(\mathrm{W} \times \mathrm{L} \times \mathrm{D}): 145 \times 239.5 \times 90 \mathrm{~cm})$.

All tanks were provided with an enriched environment consisting of natural substrate (sand or crushed coral) and either clay pots or natural rocks as dens and an air stone bubbler to increase water oxygenation and water movement in the tank [6]. Animals were fed every day, except for Sundays, with either live or dead shrimps or dead fish. The food leftovers and other waste matter were cleaned out daily.

Escape proofing tanks:

We evaluated different strategies to prevent octopuses from escaping the tank.

Tank Type 1:

1. Tank 1A-we used custom cut transparent acrylic lids with holes cut in for water inflow hose and air bubbler hose. The lids were secured to the outward facing tank rim with clamps, weights or both (Figure 2a).
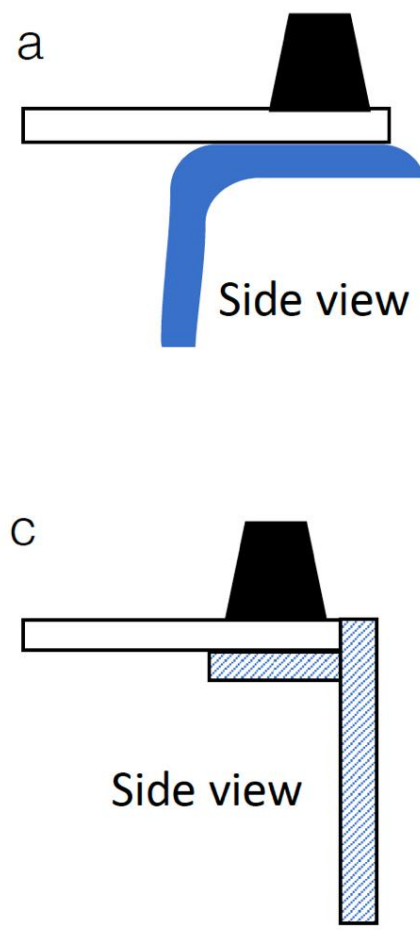
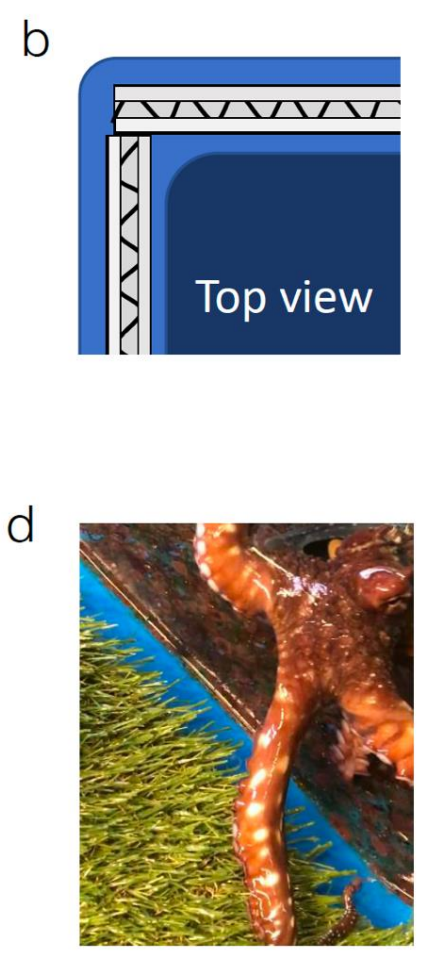

Figure 2. (a) Side view of Tank 1 A closure-A custom cut plexiglass lid was affixed and weighed down onto the outward facing rim with multiple weights. In some cases, additional clamps were used. (b) Top view of Tank 1B closure-netting was secured over the top of the tank to a fixed rail attached to the outward facing rim. Octopuses pushed the net up out of the rail specifically in the corners. (c) Side view of Type 2 tank closure-A custom cut plexiglass lid was affixed to the sunken inner facing rim. (d) Type 3 tanks were lined with artificial grass. The octopus suckers do not adhere to this texture. As long as no smooth surface outside the tank can be reached by the arms, the octopus could not pull itself out. 
2. Tank 1B-we constructed a novel type of netting closure with fastenings on the outward facing tank rim (similar netting is used in local fish farming; Figure 2b).

Tank Type 2 used custom-cut acrylic lids with holes for water inflow and an air bubbler. The lids were secured on top of the sunken inward-facing tank rim with weights (Figure 2c).

Tank Type 3 tanks did not use lids; instead, the upper part of the inner walls and outward facing tank rim were lined with artificial grass (Figure 2d).

During the period from June 2017 to October2018 we recorded for each Octopus cyanea entering the lab (for the purposes of other experiments) the date of entry into and exit from each tank. Exit from a tank was marked as either "escape", "natural death", or transferred to another tank. To assess different keeping conditions, we compared the instances of use of different tank types $(n=35)$, the duration of the tank occupancy, and the exit. In the 2 cases for which escaped octopuses survived, they were returned to the home tank and the count for number of days in tank was reset to 0 .

We compared the number of escapes and escape-related animal deaths between tank types and discussed the ease of use of the different tanks. Data analysis was done with SPSS 19 (IBM Software; Armonk, New York, NY, USA) and Microsoft Excel for Mac OS (Version 16.52, Redmond, Washington, DC, USA).

\section{Results}

\subsection{Maintenance}

Tanks of Type $1(n=17)$ and Type $2(n=9)$ both required unfastening and correct refastening of the tank lids. This procedure was done at least once a day, and on feeding days 2-3 times per day. Depending on the caretaker's experience, this procedure required at least $1 \mathrm{~min}$. Additionally, Type 2 tanks needed regular cleaning of the acrylic, which required about 3-5 min per week. Type $3(n=9)$ tanks did not require any extra time to access the interior of the tank. Type 3 tanks also needed regular cleaning of the transparent walls, which required about $3-5$ min per week.

For both Type 1 tanks, exposure to humans was limited to the tank maintenance period. In Type 1 for inspection of their general condition, octopuses often had to be coaxed out of the den. Animals in Type 2 and Type 3 tanks could choose whether to hide inside the den or sit in full view of the room (Figure 1f). It was usually possible to inspect animal condition without any specific interaction with the octopus in the tank.

\subsection{Escape}

Of a total of 29 Octopus cyanea housed between June 2017 and October 2018, there were 13 incidents of escape, all but 2 resulting in animal death (Figure 3a). The highest escape rate was from Type 1 tanks ( $n=17$ occupancies), with a total of 12 escapes. Half of the escapes occurred from Tank 1A $(n=6)$, and the other half from Tank 1B $(n=6), 10$ of which happened within the first 20 days of keeping (Figure 3b).

Type 2 tanks $(n=9)$ had no escapes (Figure 3a).

Type 3 tanks $(n=9)$ had a single escape, 8 days after introduction of the animal (Figure $3 b$ ).

The difference in escapes was compared between Tank 1 and Tank 3 . Escapes were significantly more often in Tank $1\left(n=26, \mathrm{chi}^{2}=8.3268, p=0.0039\right)$. Throughout the recorded period, Type 2 tanks were the significantly longest occupied tank with a total of 596 days $\left(n=35\right.$, chi $\left.^{2}=7.0405, p=0.029592\right)$, Type 3 tanks were occupied 296 days, while Type 1 tanks were occupied 387 days. The number of escapes was significantly higher in Tank 1 , and the number of days animals spent in the tank was not significantly different in Tank 1 and Tank $3\left(n=26\right.$, chi $\left.^{2}=0.7775, p=0.37792\right)$. 


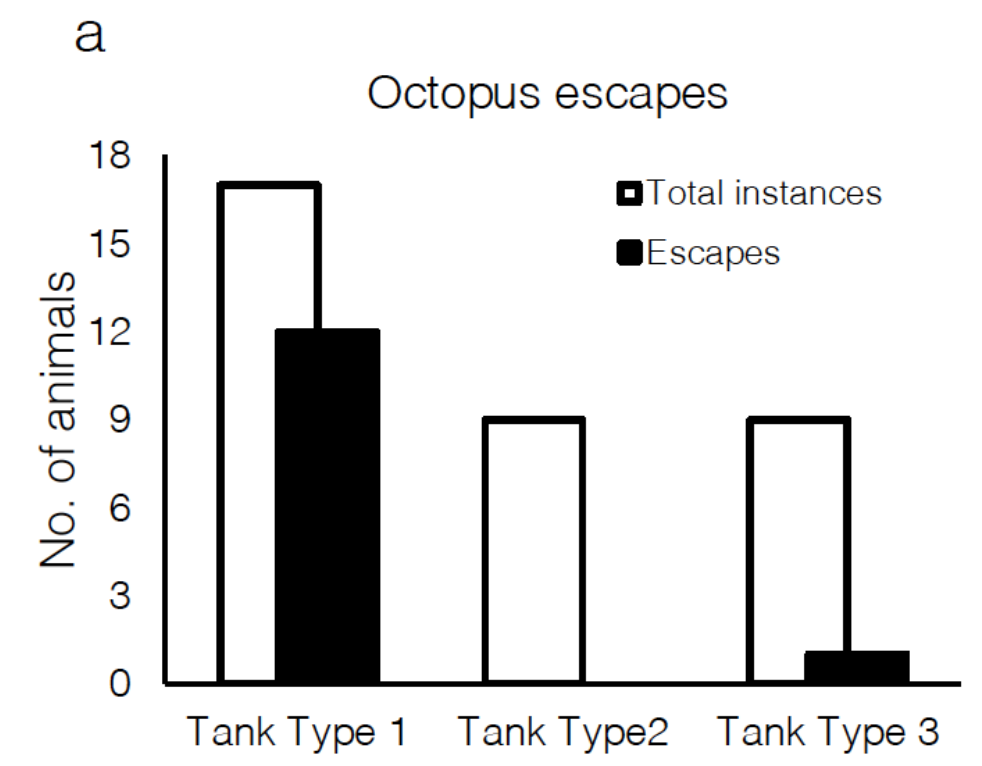

b

\section{Days housed till escape}

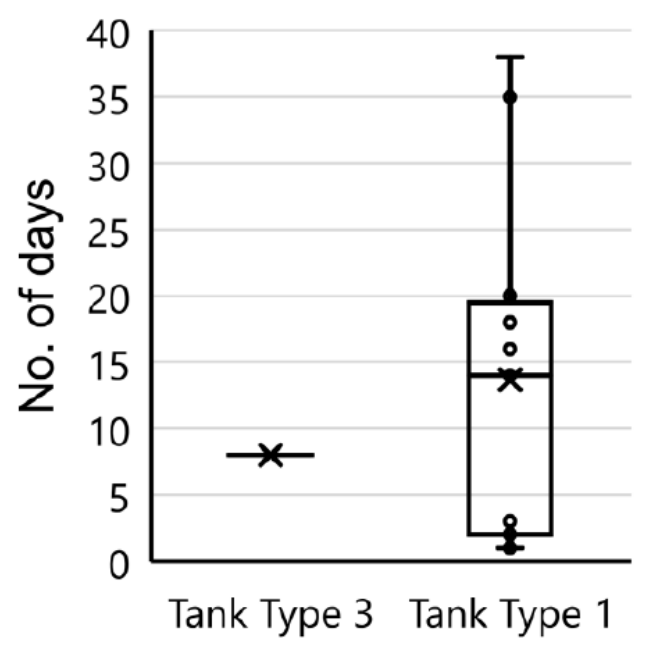

Figure 3. (a) The total number of subjects in the different tank types $(n=35)$. In total there were 13 octopus escapes. Twelve of the escapes were from Type 1 tanks, and no animals escaped from Type 2 tanks. (b) The number of days in tank before escape occurred for Type 1 and Type 3 tanks. There is a statistically significant higher number of escapes from Tank 1 than Tank $3\left(n=26, \mathrm{chi}^{2}=8.3268, p=0.0039\right)$. The majority of escapes from Type 1 tanks occurred within the first 20 days $(X$ marks average, 14 in Tank 1 , and only one single escape after 8 days in Tank 3 ).

\section{Discussion}

Our data show that the rate of octopus escapes differed greatly between the tank types (Figure 3a). This vast difference is probably the result of several factors. Both Type 1A and Type 2 tanks used a weight system (Figure 2a,c). Opening and closing these tanks is time-consuming and prone to human error in the correct placing of weights. The outwardfacing rims of Type 1A tanks were also used for fastening the lids with clamps. Due to constant interaction with salt water, clamps tended to corrode and therefore malfunction. The net system also failed to keep octopuses in the tank, as they managed to insert arms into the small gap between the net and rail in the tank corners. Therefore, the reason for the difference in number of escapes may be attributable to the difference in the tank rim. Octopus cyanea are large and can exert significant force with their arms and suckers. Once the smallest part of the arm is inserted between the lid and rim, they continue to push it through until they lift the lid $[7,13]$. This is not easily possible when the rim is sunk and inward-facing, as in Type 2 tanks (Figure 2c).

The single escape from the Type 3 tank can be attributed to damage to the artificial grass lining during a tropical storm. These tanks proved easy to maintain and clean, and in the laboratory, the setting was suitable for filming the animals' behaviors from both the side and the top (Supplementary Video S1). It is important to note that in order to prevent octopuses from using the inflow hoses to climb out, the hoses were suspended above the tank and away from the tank walls. While the tanks used in this case were exceptionally large, it is possible to use smaller tanks, provided that the depth of the lining does not allow the arm to reach out to any smooth surface. Because of this analysis, the practice of keeping octopus in Type 1 tanks was ceased.

For laboratory settings, both Type 2 and Type 3 tanks have the advantage that octopuses become acclimated to human presence, which is a benefit for both behavioral observation and animal training (Figure 2d). While Type 3 tanks must be free standing, Type 2 tanks are readily stacked into a rack system and can potentially be connected to a semi-flowthrough or fully artificial seawater system [1,6]. 
As the numbers of octopuses in laboratories, public aquaria, and aquaculture grows, information on both successes and failures in keeping become more valuable for preventing animal loss and improving animal welfare. For future studies on keeping and welfare of animals we hope for more collaborations between aquaculture $[8,14]$, research $[6,10]$, and public aquaria/zoos [15].

\section{Conclusions}

Octopuses have a very important potential as animals used in scientific research and public aquaria. It is essential to share the methodology for husbandry, welfare, and enrichment. This work presents reliable methods for escape proofing octopus tanks as well as methods to be avoided.

Supplementary Materials: The following are available online at https:/ /www.mdpi.com/article/10 .3390/app11188547/s1. Video S1: Octopus in Tank 3.

Author Contributions: Conceptualization, J.M., T.G. and M.J.K.; methodology, K.A. and T.G.; software, T.G.; validation, K.A., T.G. and M.J.K.; formal analysis, T.G.; investigation, K.A., R.N., T.N., F.Z.-K., Z.L. and T.G.; resources, J.M. and M.J.K.; data curation, K.A., T.G. and M.J.K.; writingoriginal draft preparation, K.A., T.G. and M.J.K.; writing—review and editing, K.A., R.N., T.N., F.Z.-K., Z.L., J.M. and T.G.; visualization, T.G.; supervision, T.G. and M.J.K.; project administration, J.M., T.G. and M.J.K.; funding acquisition, J.M. and M.J.K. All authors have read and agreed to the published version of the manuscript.

Funding: This work was supported by a Japanese Kakenhi C Project, code number 17K07493; from 2017-2020, for details please see https://nrid.nii.ac.jp/nrid/1000010790280/ (Accessed on 12 September 2021).

Institutional Review Board Statement: The local legal situation did not require permits for the keeping of the subjects. All animals were held according to the guidelines for the EU Directive 2010/63/EU for cephalopod welfare. There was a local keeping permit issued by the Animal Care facility at the OIST Marine Station.

Data Availability Statement: Not applicable.

Acknowledgments: We would like to thank OMSS staff for their dedicated support, namely Koichi Toda, Nobuo Ueda, and Kosuke Mori. This work was supported by a Kakenhi C Project, code number 17K07493 (for details please see https://nrid.nii.ac.jp/nrid/1000010790280/) (accessed on 12 September 2021) and the Physics and Biology Unit of the Okinawa Institute of Science and Technology Graduate University.

Conflicts of Interest: The authors declare no conflict of interest.

\section{References}

1. Di Cosmo, A.; Pinelli, C.; Scandurra, A.; Aria, M.; D'Aniello, B. Research Trends in Octopus Biological Studies. Animals 2021, 11, 1808. [CrossRef] [PubMed]

2. Gutnick, T.; Shomrat, T.; Mather, J.A.; Kuba, M.J. The Cephalopod Brain: Motion Control, Learning, and Cognition; Salleudin, S., Mukai, S., Eds.; Apple Academic Press: Watertown, MA, USA, 2016; pp. 139-177.

3. Hanlon, R.; Messenger, J. Cephalopod Behaviour; Cambridge University Press: Cambridge, UK, 2019.

4. Packard, A. Cephalopods and fish: The limits of convergence. Biol. Rev. 1972, 47, 241-307. [CrossRef]

5. Grimpe, G. Pflege, Behandlung und Zucht der Cephalopoden Fur Zoologische und Physiologische Zwecke. In Handbuch der Biologischen Arbeitsmethoden; Aberhalden, E., Ed.; Verlag Urban \& Schwarzenberg: Berlin, Germany; Wien, Austria, 1928; pp. 331-402.

6. Fiorito, G.; Affuso, A.; Basil, J.; Cole, A.; Girolamo, P.; D’Angelo, L.; Dickel, L.; Gestal, C.; Grasso, F.; Kuba, M.; et al. Guidelines for the Care and Welfare of Cephalopods in Research. Lab. Anim. 2015, 49 (Suppl. S2), 1-90. [CrossRef] [PubMed]

7. Bitterman, M.E. The Echinoderms. In Invertebrate Learning: Volume 3 Cephalopods and Echinoderms; Corning, W.C., Dyal, J.A., Willows, A.O.D., Eds.; Plenum Press: New York, NY, USA, 1975; pp. 106-109.

8. Vidal, E.; Villanueva, R.; Andrade, J.P.; Gleadall, I.; Iglesias, J.; Koueta, N.; Rosas, C.; Segawa, S.G.; Bret, F.-S.; Rita, A.; et al. Cephalopod culture: Current status of main biological models, and research priorities. In Advances in Cephalopod Science, Biology, Ecology, Cultivation and Fisheries. Advances in Marine Biology; Vidal, E.A.G., Ed.; Academic Press: London, UK, 2014; Volume 67, pp. 1-98. 
9. Rodriguez, C.; Carrasco, J.F.; Arronte, J.C.; Rodriguez, M. Common octopus (Octopus vulgaris Cuvier, 1797) juvenile on growing in floating cages. Aquaculture 2006, 254, 293-300. [CrossRef]

10. Fiorito, G.; Affuso, A.; Anderson, D.B.; Basil, J.; Bonnaud, L.; Botta, G.; Cole, A.; D’Angelo, L.; De Girolamo, P.; Dennison, N.; et al. Cephalopods in neuroscience: Regulations, research and the 3Rs. Invertebr. Neurosci. 2014, 14, 13-36. [CrossRef] [PubMed]

11. Boletzky, S.v.; Hanlon, R.T. A review of the laboratory maintenance, rearing and culture of cephalopod molluscs. Mem. Natl Mus. Vic. 1983, 44, 147-187. [CrossRef]

12. Sanders, G.D. The Cephalopods. In Invertebrate Learning: Volume 3 Cephalopods and Echinoderms; Corning, W.C., Dyal, J.A., Willows, A.O.D., Eds.; Plenum Press: New York, NY, USA, 1975; pp. 1-101.

13. Wells, M.J. Physiology and Behaviour of an Advanced Invertebrate. In Octopus; Chapman and Hall: London, UK; New York, NY, USA, 1978

14. Kolkovski, S.; King, J.; Watts, N.; Natale, M.; Mori, A.; Cammilleri, R.; Cammilleri, C. Development of octopus aquaculture. In Fisheries Research Report; No. 262; Department of Fisheries Western Australia: Perth, Australia, 2015; ISBN 978-1-921845-84-0. Available online: http://www.fish.wa.gov.au/Documents/research_reports/frr262.pdf (accessed on 10 August 2021).

15. Fernandez, E.J.; Timberlake, W. Mutual benefits of research collaborations between zoos and academic institutions. Zoo Biol. 2008, 27, 470-487. [CrossRef] [PubMed] 